\title{
Development of a simplified thermal performance prediction method based on free-running temperatures and building envelope characteristics
}

\author{
Xinying Fan ${ }^{1}$, Bin Chen ${ }^{1}$, Xiang $\mathrm{Li}^{1}$, Changfeng $\mathrm{Fu}^{2}$, Lingyun $\mathrm{Li}^{1}$ \\ Dalian University of Technology, China ${ }^{1}$
}

The University of West London, $\mathrm{UK}^{2}$

\begin{abstract}
Various thermal prediction methods and tools for conceptual building design have been rapidly developed in the past decades. However, most of these methods have some drawbacks to obsess their applications, such as heavily relying on very detailed information of building envelope components, and their thermal conductivity data with complicated computation models or formulas; and difficulties for architects to understand and judge the outcomes of such predictions in a conceptual design. Therefore, this research targets on developing a simplified method to predict the integrated thermal performance of a building with simplified envelope parameters and hourly free-running temperatures in the conceptual design stage. It categorizes the scattered design parameters into three combined thermal characteristic indexes and applies a serials of corresponding quasi-steady calculation methods for building thermal processes to predict hourly free-running temperatures. The interrelationships between these three combined indexes and two overall thermal performance indicators are verified via a sensitivity analysis, and are presented in two charts, which can easily be adopted in a conceptual building design. This method has been validated in an experimental case study. It can help architects to quickly find the thermal design performance of a designed building in the conceptual design stage.
\end{abstract}

Key Words: envelope thermal design, free-running temperature, conceptual design, overall thermal performance prediction 


\section{Nomenclature}

$G_{\text {to }} \quad$ total solar heat-gain index, W

$K_{\text {to }} \quad$ total heat-loss index, W/K

$S_{\text {to }} \quad$ total effective heat-capacity index, $\mathrm{kJ} / \mathrm{K}$

$A_{\text {win }} \quad$ area of the direct-gain windows, $\mathrm{m}^{2}$

$S H G C_{\text {win }}$ solar gain coefficient of the direct-gain windows which based on Chinese design standards

$G \quad$ direct gain from the glass panels of windows, $\mathrm{W} / \mathrm{m}^{2}$

$Q_{\mathrm{g}}^{j} \quad$ building's total heat-gain at time $j, \mathrm{~kJ}$

$k_{\mathrm{s}} \quad$ heat transfer coefficient of an external envelope component, $\mathrm{W} /\left(\mathrm{m}^{2} \cdot \mathrm{K}\right)$

$A_{\mathrm{s}} \quad$ area of a wall component, $\mathrm{m}^{2}$

$n \quad$ infiltration rate of indoor space, $\mathrm{h}^{-1}$

$\rho_{\mathrm{a}} \quad$ density of indoor air, $\mathrm{kg} / \mathrm{m}^{3}$

$\mathrm{C}_{\mathrm{a}} \quad$ heat specific of indoor air, $\mathrm{kJ} /(\mathrm{kg} \cdot \mathrm{K})$

$V_{\mathrm{a}} \quad$ volume of indoor space, $\mathrm{m}^{3}$

$T_{\mathrm{o}}^{j} \quad$ outdoor air temperature at time $j, \mathrm{~K}$

$T_{\mathrm{a}}^{j} \quad$ indoor air temperature at time $j, \mathrm{~K}$

$\rho_{\mathrm{s}} \quad$ density of an indoor-side layer of an opaque envelope component, $\mathrm{kg} / \mathrm{m}^{3}$

$C_{\mathrm{s}} \quad$ specific heat, $\mathrm{kJ} /(\mathrm{kg} \cdot \mathrm{K})$

$\delta_{\mathrm{s}} \quad$ depth of effective heat capacity layer, $\mathrm{m}$

$\tau \quad$ time period, $s$

$\lambda_{\mathrm{s}} \quad$ thermal conductivity coefficient of indoor-side layer of envelope component, $\mathrm{W} /(\mathrm{m} \cdot \mathrm{K})$

$Q_{\mathrm{s}}^{j} \quad$ building total heat-storage or heat-loss at time $j, \mathrm{~kJ}$

$T_{\mathrm{s}} \quad$ average temperature of the inside layer, $\mathrm{K}$

$\Delta T_{\mathrm{io}} \quad$ indoor-outdoor average temperature difference of the free-running building, $\mathrm{K}$

$\alpha_{\mathrm{io}} \quad$ ratio of indoor and outdoor daily temperature amplitude

$Q_{\mathrm{a}}^{j} \quad$ heat variation of indoor air from time $j-1$ to time $j, \mathrm{~kJ}$

$Q_{l}^{j} \quad$ total heat-loss, $\mathrm{kJ}$

$Q_{\mathrm{s}}^{j} \quad$ total heat-storage or heat-loss, $\mathrm{kJ}$

$h_{\mathrm{c}} \quad$ coefficient of convective heat transfer, $\mathrm{W} /\left(\mathrm{m}^{2} \cdot \mathrm{K}\right)$

$n \quad$ infiltration rate

$g \quad$ total ratio of solar radiation of the transparent area of a door and a window

$A_{g} \quad$ area of the transparent part of a door and a window, $\mathrm{m}^{2}$

$\eta_{s} \quad$ solar radiation absorption coefficient of non-transparent parts in doors and windows

$k_{n o n-t r} \quad$ heat transfer coefficient of the non-transparent parts of doors and windows, $\mathrm{W} /\left(\mathrm{m}^{2} \bullet \mathrm{K}\right)$

$h_{\mathrm{e}} \quad$ convective heat transfer coefficient of outer surfaces, $\mathrm{W} /\left(\mathrm{m}^{2} \cdot \mathrm{K}\right)$

$A_{f} \quad$ area of the non-transparent part of doors and windows, $\mathrm{m}^{2}$

$\phi \quad$ correction coefficient considered linear heat loss through thermal bridges

$k_{\mathrm{d}} \quad$ heat transfer coefficient of the ground floor, $\mathrm{W} /\left(\mathrm{m}^{2} \cdot \mathrm{K}\right)$

$A_{\mathrm{d}} \quad$ area of the ground floor, $\mathrm{m}^{2}$

HVAC Heating, Ventilation and Air Conditioning

\section{Subscripts}

$j \quad$ time interval sequence number 


\section{Introduction}

Free-running temperature is the indoor temperature of a building running without a HVAC (Heating, Ventilation and Air Conditioning) system [1-5]. Ensuring satisfactory free-running temperatures to achieve a desired indoor thermal performance via well-designed building envelopes in a concept design is an essential procedure and a common approach for sustainable building design [6,7]. The thermal performance of building envelopes has also a significant impact on the energy consumption of a building [8]. However, most thermal performance prediction methods with many complex formulas of calculating thermal performance of individual envelope components or a whole building are too complicated for architects in a conceptual design [9-11]. The most existing calculation methods of envelope thermal parameters and the existing evaluation methods of dynamic building thermal performance primarily reply on complex simulation tools such as EnergyPlus, eQUEST, DeST etc., with very detailed thermal conductivity information of building envelop components [12-14]. They are too complex for a conceptual design $[15-18]$

Therefore, an easy-to-use method for thermal performance prediction in the conceptual design stage is demanded $[9,17]$, which should be able to explain building physical phenomena properly, and to present optimal solutions [13]. Several simplified building thermal models have been developed so far $[3,17,19,20]$. It is common to adopt combined thermal indexes to present some specific building thermal characteristics, such as a total heat loss coefficient and a total effective heat capacity. These combined thermal indexes can represent the thermal characteristics of a building, and also can be easily understood by both architects and engineers [3]. However, very few of these methods can analyze the whole building dynamic thermal processes with these combined indexes and simple corresponding calculation methods. For example, the steady prediction model only uses a total heat-gain $G_{\text {to }}$ and a total heat loss coefficient $K_{\text {to }}$ to calculate a 
building static thermal process; and the quasi-steady prediction model mainly are based on a combined thermal index or a simplified model which can calculate dynamic heat storage, including total effective heat capacity, thermal time constant $[3,20]$. This study aims to develop an easy-to-use prediction method based on three combined thermal indexes (a total heat-gain $G_{\mathrm{to}}$, which present the heat-gain performance of an overall building envelope; a total heat-loss coefficient $K_{\mathrm{to}}$, which present the heat-isolation performance of an overall building envelope; a total effective heat capacity $S_{\text {to }}$, which present the heat capacity performance of an overall building envelope). Furthermore, this method can accurately predict the hourly free-running temperatures of a designed building.

Usually, the methods of a static building thermal process based on $G_{\mathrm{to}}$ and $K_{\mathrm{to}}$ are simple and easy-to-use in the conceptual design stage [3]. Nevertheless, although the quasi-steady algorithm of the dynamic thermal behavior of thermal mass based on $S_{\text {to }}$ is suitable for conceptual design, the precise prediction of $S_{\text {to }}$ must rely on the detailed simulation tools or elaborate algorithms [20-22], which is too complicated in the conceptual design stage [9]. Therefore, a simple and precise solution for $S_{\text {to }}$, needs to be developed in this study.

The simplified prediction method can also establish the precise interrelationships between the free-running temperature indicators and the three combined thermal indexes. This can help designers to understand the thermal characteristics of building envelopes, and their impacts on free-running temperatures. Previous sensitivity analysis studies had already been carried out by using some detailed simulation tools to investigate interrelationships between thermal design parameters of an envelope and an overall building energy performance index. This has been proven as an effective way to guide thermal design and to support thermal design decision-making procedures [23,24]. However, some non-linear interactions and distinctions of physical-dimensions among numerous scattered design parameters will limit a 
multiple-factor sensitivity analysis [25]. This study attempted to apply a set of combined thermal indexes with a unified dimension in the sensitivity analysis to investigate the multiple-factor effect. In addition, the interrelationships between three combined thermal indexes and free-running temperatures can not only demonstrate the formulas of a building thermal design, but also provide with a simple prediction on the thermal parameters of an envelope according to the desired free-running temperatures.

\section{Research methods}

This study uses three combined indexes (a total heat-gain $G_{\text {to }}$, a total heat-loss coefficient $K_{\text {to }}$, and a total effective heat capacity $S_{\text {to }}$ ) and the relevant and simplified formulas to create a quasi-steady thermal process, which could predict hourly free-running temperatures. Based on a building heat balance analysis, the quasi-steady approach is often used in some simplified building thermal methods to predict the dynamic cooling or heating load [20-22]. The quasi-steady method considers the heat conductivity between the interior layer and the exterior layer of a building envelope component as a steady process, and the heat storage of interior thermal mass as a quasi-steady process. The heat storage usually can be calculated with a

combined index, such as $S_{\text {to }}$ [22]. The accuracy of the quasi-steady model relies on the accuracy of the combined index, which can be worked out with a detailed simulation tool or with elaborate algorithms manually $[20,21,26]$.

In order to precisely and easily obtain $S_{\text {to }}$ in a conceptual design, the study applies concept about the surface effective heat capacity layer [20], and the formula based on a periodic penetration depth to calculate the depth of the surface effective heat capacity layer of an envelope [26]. This surface effective heat capacity layer principle demonstrates that only a very thin interior layer of a wall has effect on indoor thermal stability. The periodic penetration depth, where the amplitude of a periodic heat wave decreases to 
1/e, is a semi-empirical definition, which describes the rapid attenuation phenomenon of a periodic heat wave through a wall $[20,26,27]$. Because of this, the calculation for an effective heat capacity $S_{\text {to }}$ can be done easily in a conceptual design.

The following three combined indexes were used in the quasi-steady model:

- a total solar heat-gain index $G_{\text {to }}(\mathrm{W})$,

- a total heat-loss index $K_{\text {to }}(\mathrm{W} / \mathrm{K})[3]$,

- a total effective heat-capacity index $S_{\text {to }}(\mathrm{kJ} / \mathrm{K})$ [20-22].

The associated calculation methods of the three combined thermal indexes are defined below.

A total solar heat-gain index $G_{\text {to }}(\mathrm{W})$ can be calculated using the formula (1), since solar radiation is considered as a main heating source in the conceptual design stage. The formula (2) was used to calculate the $S H G C_{\text {win }}$ of the formula (1). Thus, the value of $G_{\text {to }}$ (W) can be used to evaluate the heat-gain performance of an envelope component.

$$
\begin{gathered}
G_{\text {to }}=A_{\text {win }} S H G C_{\text {win }} G \\
S H G C_{w i n}=\frac{\sum g \times A_{g}+\sum \eta_{s} \times \frac{k_{\text {non-tr }}}{h_{e}} \times A_{f}}{A_{w}}
\end{gathered}
$$

where $A_{\text {win }}\left(\mathrm{m}^{2}\right)$ is the area of direct-gain windows; $S H G C_{\text {win }}$ is the solar gain coefficient of direct-gain windows which are based on the Chinese design code, and $G\left(\mathrm{~W} / \mathrm{m}^{2}\right)$ is the direct gain from the glass panels of windows; $g$ is the total ratio of solar radiation of the transparent area of a door and a window; $A_{g}$ $\left(\mathrm{m}^{2}\right)$ is the area of the transparent part of a door and a window; $\eta_{s}$ is the solar radiation absorption coefficient of non-transparent parts in doors and windows; $k_{\text {non-tr }}\left[\mathrm{W} /\left(\mathrm{m}^{2} \bullet \mathrm{K}\right)\right]$ is the heat transfer coefficient of the non-transparent parts of doors and windows; $h_{\mathrm{e}}\left[\mathrm{W} /\left(\mathrm{m}^{2} \cdot \mathrm{K}\right)\right]$ is convective heat transfer coefficient of outer surfaces; $A_{f}\left(\mathrm{~m}^{2}\right)$ is the area of the non-transparent part of doors and windows. 
The total heat-loss index $K_{\mathrm{to}}(\mathrm{W} / \mathrm{K})$ can be calculated using the formula (3). The total heat-loss via the insulation and infiltration characteristics of an envelope were considered in the formula (3). Thus, the value of $K_{\text {to }}(\mathrm{W} / \mathrm{K})$ could be used to evaluate the heat-isolation performance of an envelope.

$$
K_{\mathrm{to}}=\sum\left(\phi k_{\mathrm{s}} A_{\mathrm{s}}+k_{d} A_{d}\right)+\frac{n \rho_{\mathrm{a}} \mathrm{C}_{\mathrm{a}} V_{\mathrm{a}}}{3.6}
$$

where $k_{\mathrm{s}}\left(\mathrm{W} /\left(\mathrm{m}^{2} \cdot \mathrm{K}\right)\right)$ is the heat transfer coefficient of an external envelope component; $\phi$ is the correction coefficient considered linear heat loss through thermal bridges, $A_{\mathrm{s}}\left(\mathrm{m}^{2}\right)$ is the area of a wall component; $k_{\mathrm{d}}\left(\mathrm{W} /\left(\mathrm{m}^{2} \cdot \mathrm{K}\right)\right)$ is the heat transfer coefficient of the ground floor; $A_{\mathrm{d}}\left(\mathrm{m}^{2}\right)$ is the area of the ground floor; $n\left(\mathrm{~h}^{-1}\right)$ is the infiltration rate of indoor space; $\rho_{\mathrm{a}}\left(\mathrm{kg} / \mathrm{m}^{3}\right)$ is the density of indoor air; $\mathrm{C}_{\mathrm{a}}$ $(\mathrm{kJ} /(\mathrm{kg} \cdot \mathrm{K}))$ is the specific heat of indoor air; and $V_{\mathrm{a}}\left(\mathrm{m}^{3}\right)$ is the volume of indoor space.

The total effective heat capacity index $S_{\mathrm{to}}(\mathrm{kJ} / \mathrm{K})$ can be calculated with formula (4) [22]. $S_{\mathrm{to}}(\mathrm{kJ} / \mathrm{K})$ is the total effective heat capacity of those opaque components of an envelope. The formula (5) was used to calculate the $\delta_{\mathrm{s}}(\mathrm{m})$ of the formula (4).

$$
\begin{gathered}
S_{\mathrm{to}}=\sum \rho_{\mathrm{s}} C_{\mathrm{s}} A_{\mathrm{s}} \delta_{\mathrm{s}} \approx \sum A_{\mathrm{s}} \sqrt{\frac{\tau}{\pi} \rho_{\mathrm{s}} C_{\mathrm{s}} \lambda_{\mathrm{s}}} \\
\delta_{\mathrm{s}}=\sqrt{\frac{\tau}{\pi} \frac{\lambda_{\mathrm{s}}}{\rho_{\mathrm{s}} C_{\mathrm{s}}}}
\end{gathered}
$$

where $\rho_{\mathrm{s}}\left(\mathrm{kg} / \mathrm{m}^{3}\right)$ is the density of an indoor-side layer of an opaque envelope component; $C_{\mathrm{s}}(\mathrm{kJ} /(\mathrm{kg} \cdot \mathrm{K}))$ is specific heat; and $\delta_{\mathrm{s}}(\mathrm{m})$ is the depth of effective heat capacity layer which can be semi-experimentally calculated by the periodic penetration depth formula [26]; $\tau$ (s) is a time period, which is set as 3600s interval since a prediction time interval of one hour was used in this study, and $\lambda_{\mathrm{s}}(\mathrm{W} /(\mathrm{m} \cdot \mathrm{K}))$ is thermal conductivity coefficient of indoor-side layer of envelope component.

This quasi-steady method has also been validated with two different methods. The first one is to make a 
comparison of the predicted results from the quasi-steady model and the simulation outcomes of the EnergyPlus - a detailed thermal process prediction software. The second validation is based on the measured data on site. The first validation adopts two BESTEST (building energy simulation test) buildings, which are usually used as the standard test buildings for building energy analysis with computer programs or algorithms, one test building with light-weight envelope materials and another with heavy weight materials [28]. The hourly free-running temperatures of the two BESTEST buildings were simulated by EnergyPlus with the annual weather data of Denver, Colorado. Meanwhile, another validation is based on the measured historical data of two free-running experimental buildings over a month in Dalian, Liaoning. Furthermore, in order to investigate the interrelation between thermal characteristics of an envelope (heat-gain performance, heat-isolation performance, and heat storage performance) and overall building thermal performance based on free-running temperatures, the study analyzes the interrelation between the three combined indexes $\left(G_{\mathrm{to}}, K_{\mathrm{to}}\right.$, and $\left.S_{\mathrm{to}}\right)$ and two overall thermal performance indicators (the temperature difference between interior and exterior $\Delta T_{\mathrm{io}}$, and a ratio of the daily range between the interior and exterior $\alpha_{\mathrm{io}}$ ) by the sensitivity analysis method. The physical meanings of the five sensitivity analyses are shown in Figure 1. Compared to the previous sensitivity analysis studies with numerous analysis parameters, this study only used three combined thermal indexes on the same physical-dimensions to avoid non-linear interactions in a multiple-factor analysis $[24,25]$, and greatly reduced the workload and complexity. In addition, the interrelations between the five sensitivity analysis indexes and macroscopic physical meaning can also reveal an overview thermal performance of an envelope component and a whole building.

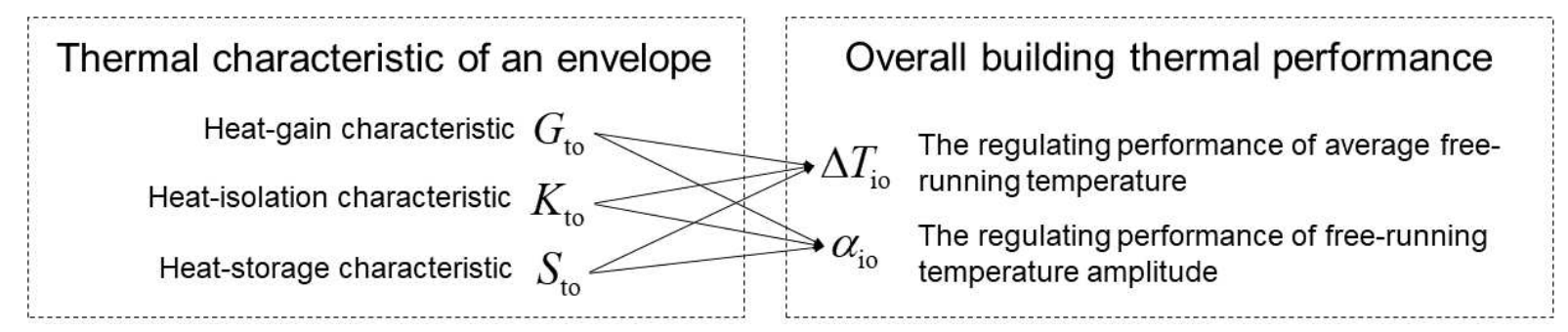


Figure 1 The sensitivity analysis indexes

\section{A simple quasi-steady method to predict free-running temperature}

\subsection{Modeling approach for the free-running temperature Prediction}

Based on three combined thermal indexes and the associated quasi-steady calculation methods, the formula of free-running temperature can be developed based on the heat balance of indoor air. The heat-balance equation can be expressed as:

$$
Q_{\mathrm{a}}^{j}+Q_{l}^{j}+Q_{\mathrm{s}}^{j}+Q_{\mathrm{g}}^{j}=0
$$

where $Q_{\mathrm{a}}^{j}(\mathrm{~kJ})$ is the heat variation of indoor air from time $j-1$ to time $j ; Q_{l}^{j}(\mathrm{~kJ})$ is the total heat-loss; $Q_{\mathrm{s}}^{j}(\mathrm{~kJ})$ is the total heat-storage or heat-loss, and $Q_{\mathrm{g}}^{j}(\mathrm{~kJ})$ is the total heat-gain. In the formula $(6), Q_{l}^{j}$ $(\mathrm{kJ}), Q_{\mathrm{s}}^{j}(\mathrm{~kJ})$, and $Q_{\mathrm{g}}^{j}(\mathrm{~kJ})$ can be separately calculated using the formula (7), (8), and (9). In addition, $Q_{\mathrm{a}}^{j}(\mathrm{~kJ})$ can be calculated with the formula (10) according to its definition.

A building total heat storage or heat-loss $Q_{l}^{j}(\mathrm{~kJ})$ at time $j$ can be figured out with the formula (7) based on a $K_{\text {to }}(\mathrm{W} / \mathrm{K})$,

$$
Q_{l}^{j}=3.6 K_{\mathrm{to}}\left(T_{\mathrm{o}}^{j}-T_{\mathrm{a}}^{j}\right)
$$

where $T_{\mathrm{o}}^{j}(\mathrm{~K})$ is the outdoor air temperature at time $j$ and $T_{\mathrm{a}}^{j}(\mathrm{~K})$ is the indoor air temperature at time $j$.

A building total heat-storage or heat-loss $Q_{\mathrm{s}}^{j}(\mathrm{~kJ})$ at time $j$ can be calculated with the formula (8) based on $S_{\text {to }}(\mathrm{kJ} / \mathrm{K})$. This means that the heat transferring process between the inside layer of a wall and the indoor air has reached a balance point, i.e. the average temperature of the inside layer, $T_{\mathrm{s}}(\mathrm{K})$ is equal to the indoor air temperature $T_{\mathrm{a}}(\mathrm{K})$.

$$
Q_{\mathrm{s}}^{j}=S_{\mathrm{to}}\left(T_{a}^{j}-T_{s}^{j-1}\right)
$$

where $T_{\mathrm{s}}^{j-1}(\mathrm{~K})$ is the average temperature of the indoor-side layer of the component at time $j-1$.

A building's total heat-gain $Q_{\mathrm{g}}^{j}(\mathrm{~kJ})$ at time $j$ can be calculated with the formula (9) based on a $G_{\text {to }}(\mathrm{W})$, 


$$
Q_{\mathrm{g}}^{j}=3.6 G_{\text {to }}^{j}
$$

where 3.6 is the coefficient that converts the dimension from $\mathrm{W}$ to $\mathrm{kJ}(1 \mathrm{~kJ}=3600 \mathrm{~s} \times 1 \mathrm{~W} / 1000), j$ is the time interval sequence number, and the prediction time interval is set as one hour in this study.

A heat variation of indoor air $Q_{\mathrm{a}}^{j}(\mathrm{~kJ})$ can be calculated with the formula (10) based on its definition.

$$
Q_{\mathrm{a}}^{j}=\rho_{\mathrm{a}} \mathrm{C}_{\mathrm{a}} V_{\mathrm{a}}\left(T_{\mathrm{a}}^{j}-T_{\mathrm{a}}^{j-1}\right)
$$

Input the outcomes from formula (7), (8), (9), and (10) into formula (6), the prediction of an indoor air temperature at time $j$ can be worked out with the formula (11) below:

$$
T_{\mathrm{a}}^{j}=\frac{3.6 K_{\mathrm{to}} T_{\mathrm{o}}^{j}-\rho_{\mathrm{a}} \mathrm{C}_{\mathrm{a}} \mathrm{V}_{\mathrm{a}} T_{\mathrm{a}}^{j-1}+S_{\mathrm{to}} T_{\mathrm{s}}^{j-1}+3.6 G_{\mathrm{to}}^{j}}{3.6 K_{\mathrm{to}}-\rho_{\mathrm{a}} \mathrm{C}_{\mathrm{a}} \mathrm{V}_{\mathrm{a}}+S_{\text {to }}}
$$

The formula (11) includes two unknown variables, $T_{\mathrm{a}}^{j}$ and $T_{\mathrm{s}}^{j-1}$. In order to work out the indoor air temperature and the internal surface average temperature of an envelope, another heat-balance formula (12) was developed, which considers the heat conducting process between an effective heat capacity layer and an indoor air temperature, and is expressed as:

$$
S_{\mathrm{to}}\left(T_{\mathrm{s}}^{j}-T_{\mathrm{s}}^{j-1}\right)=3.6 A_{\mathrm{s}} \mathrm{h}_{\mathrm{c}}\left(T_{\mathrm{a}}^{j}-T_{\mathrm{s}}^{j}\right)
$$

where $\mathrm{h}_{\mathrm{c}}\left(\mathrm{W} /\left(\mathrm{m}^{2} \cdot \mathrm{K}\right)\right)$ is the coefficient of convective heat transfer, which is approximately set to 3.08 for free-running building [29-31]. The formula (12) can be transformed to the formula (13) which describes the internal surface average temperature of an envelope:

$$
T_{\mathrm{s}}^{j}=\frac{S_{\mathrm{to}} T_{\mathrm{s}}^{j-1}+3.6 A_{\mathrm{s}} \mathrm{h}_{\mathrm{c}} T_{\mathrm{a}}^{j}}{S_{\mathrm{to}}+3.6 A_{\mathrm{s}} \mathrm{h}_{\mathrm{c}}}
$$

Finally, the free-running temperature and the internal surface average temperature can be iteratively calculated with the formulas (11) and (13). 


\subsection{Application scope of the quasi-steady model}

The procedure for predicting free-running temperatures with the formula (11) and (13) only requires outdoor weather data, major building dimensions, and the thermal design data sets of envelopes, which are shown in Figure 2. The three combined thermal indexes could be rapidly determined according to hourly weather data (hourly solar radiation $G^{j}$ ), building dimensions (window area $A_{\text {win }}$, other opaque component area $A_{\mathrm{s}}$, and indoor space volume $V_{\mathrm{a}}$ ), and the building thermal design codes (heat transfer coefficient $k_{\mathrm{s}}$, infiltration rate $n$, thermophysical parameters of building materials $\rho_{\mathrm{s}}, C_{\mathrm{s}}$, and $\left.\lambda_{\mathrm{s}}\right)$. Substituting of the initial temperature, boundary condition, and three combined indexes into the iterative formulas (11) and (13) can predict hourly free-running temperatures and internal surface average temperatures. The iterative formulas can be run in Excel easily and the results can be presented in a chart.

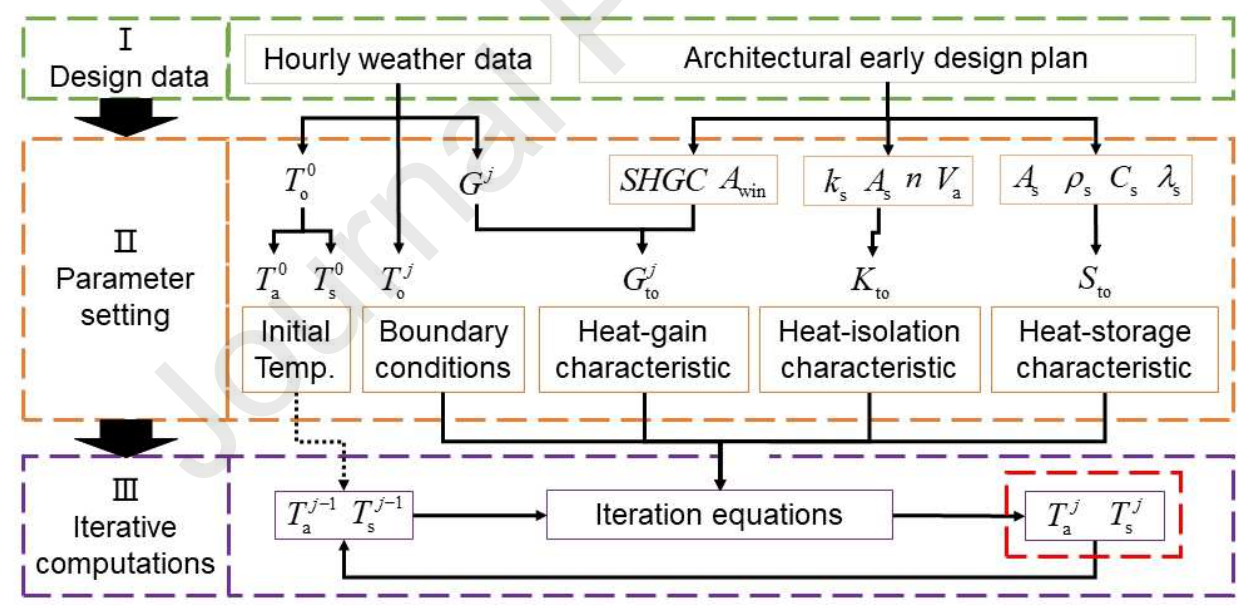

Figure 2 The prediction procedure of free-running temperature using the quasi-steady model

The prediction procedure indicates that this quasi-steady model does not require the detailed configurations of an envelope. In addition, a serials of parameters with clear physical meaning are easily obtained, and the iterative computation with an Excel chart can be checked quickly and easily. Thus, this quasi-steady model can be easily handled in the conceptual design stage of a building project, which requires a simplified model to dynamically evaluate the overall thermal performance of a conceptual design with limited 
information.

\subsection{Validation of the model}

In order to validate this quasi-steady method, a simulation was carried out with EnergyPlus, and an experimental case study with the measured data was also conducted. In the simulation, two BESTEST buildings (one with light-weight envelops, and another with heavy-weight) were adopted as the test buildings. The hourly free-running temperatures of the two BESTEST buildings are predicted in EnergyPlus with the annual weather data of Denver, Colorado. Meanwhile, the one-month measured temperatures from two free-running experimental buildings in Dalian, China were used in the experimental validation. The following sections give the details of the two validations.

\subsubsection{Comparison validation}

The Figure 3 shows the dimensions of the BESTEST buildings.

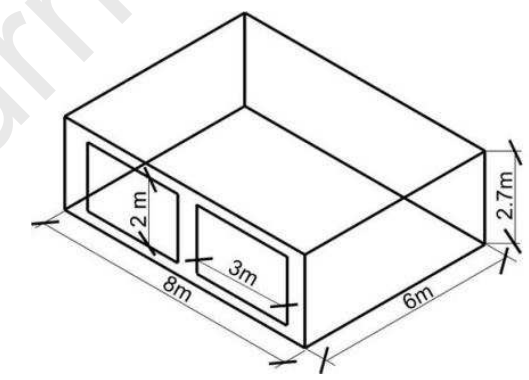

Figure 3 Dimensions of the BESTEST building.

The detailed envelope configuration and the thermal conductivity parameters of the envelopes of the two

BESTEST buildings are given in Table 1, and the infiltration rate of both buildings was set as $0.5 \mathrm{~h}^{-1}$.

Table 1 The envelope configuration and envelope thermal parameters of the two BESTEST buildings (XPS - Extruded polystyrene, MW - mineral wool, UF - urea formaldehyde).

\begin{tabular}{ccccc}
\hline Buildings & Envelope & $\begin{array}{c}\text { Configuration } \\
(\mathrm{mm})\end{array}$ & $\begin{array}{c}k_{\mathrm{s}} \\
\mathrm{W} /\left(\mathrm{m}^{2} \bullet \mathrm{K}\right)\end{array}$ & $\begin{array}{c}S_{\mathrm{s}} \\
\mathrm{kJ} / \mathrm{K}\end{array}$ \\
\hline Light & Wall & Gypsum board (13) +XPS (128) + metallic cladding (6) & 0.50 & 744 \\
weight & Roof & Gypsum board (13) + air gap (200) + MW glass wool (251) + asphalt (10) & 0.39 & 561
\end{tabular}




$\begin{array}{cccc} & \text { Floor } & \text { Wooden floor }(30)+\text { screed }(70)+\text { concrete }(100)+\text { UF Foam }(239) & 0.46 \\ & \text { Windows } & \text { Double glazing timber frame window }(S H G C=0.56) & 2.71\end{array}$

The EnergyPlus simulation results based on the building dimensions (Figure 3) and the building envelop configuration (Table 1) are presented in the Figure $4 \mathrm{a}$ and $4 \mathrm{~b}$. In this simulation, the time interval within every hour was set as 10 minutes; the solar distribution was chosen as the full exterior; the solution algorithm was chosen as the CTF; the inside and outdoor convection algorithm were respectively chosen as the TARP algorithm and the DOE-2 algorithm. On the other hand, the combined thermal indexes $K_{\text {to }}(\mathrm{W} / \mathrm{K})$ and $S_{\text {to }}(\mathrm{kJ} / \mathrm{K})$ are obtained from the building dimensions (Figure 3) and the building envelop materials (Table 1). The $G_{\text {to }}^{j}(\mathrm{~W})$ data are from EnergyPlus calculation file since the hourly solar radiation on the vertical windows panel is absent in the weather file. Then, the initial temperatures are based on the EnergyPlus results, the hourly outdoor temperature in Denver, the $G_{\mathrm{to}}^{j}(\mathrm{~W}), K_{\mathrm{to}}(\mathrm{W} / \mathrm{K})$, and $S_{\text {to }}(\mathrm{kJ} / \mathrm{K})$ were substituted into the formula (11) and (13). This allowed the hourly free-running temperature over a year to be calculated by this quasi-steady model, as shown in Figure 4. It shows that the variation tendency of the hourly free-running temperatures predicted by the EnergyPlus and this quasi-steady model is very similar to each other. In addition, the SD (Standard Deviation) error bars show that the dispersion degree of the results predicted by this quasi-steady method and EnergyPlus is also very close, although the distribution ranges of the hourly free-running temperatures predicted by this quasi-steady model is slightly lower than EnergyPlus. 


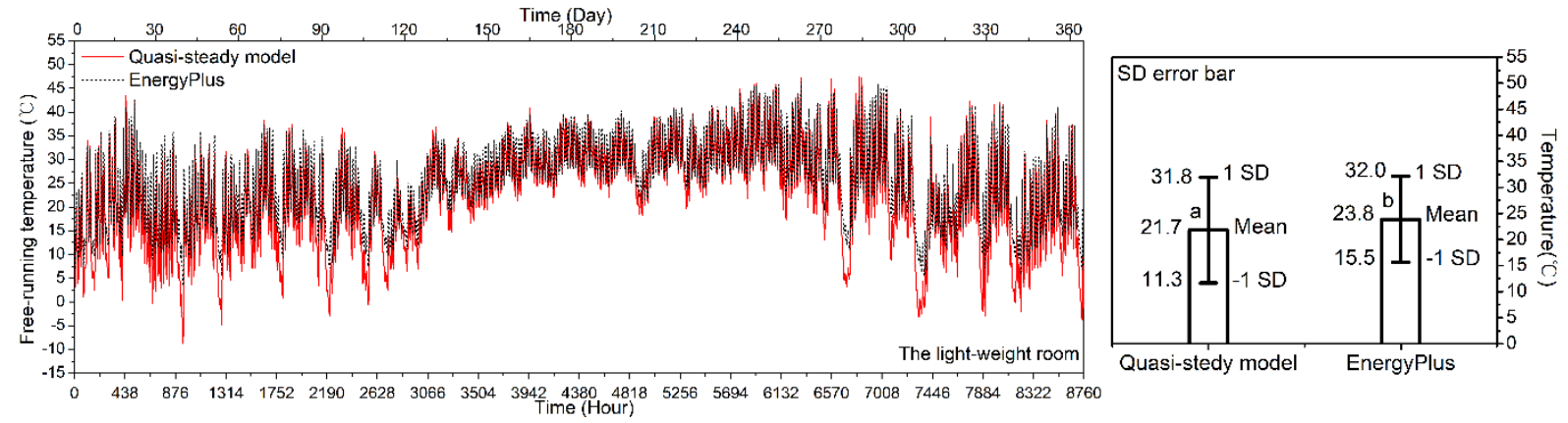

a. BESTEST building with light-weight envelops

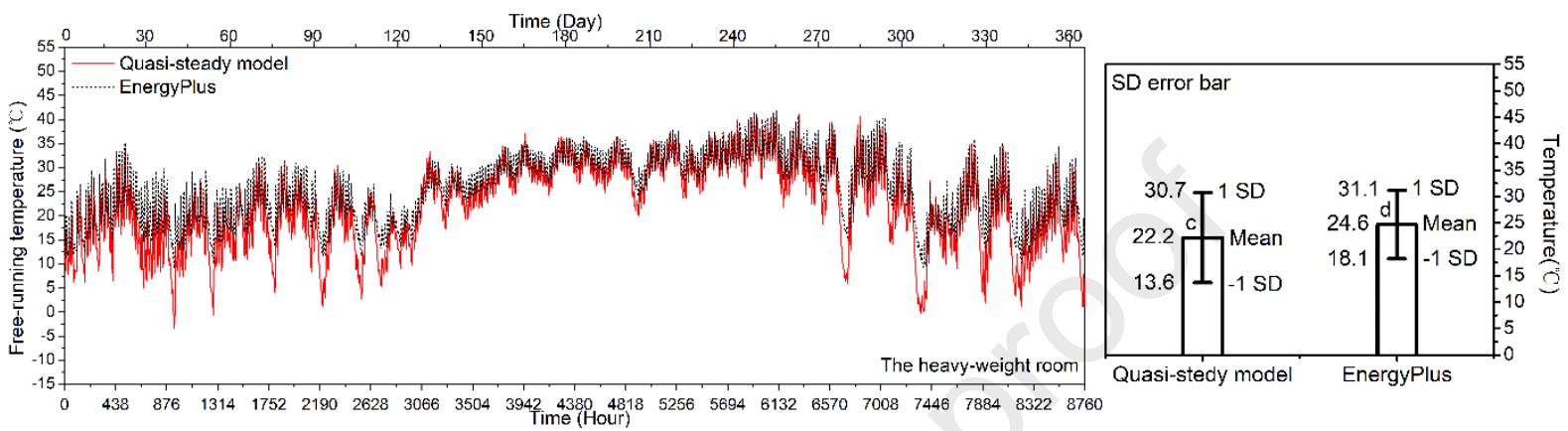

b. BESTEST building with heavy-weight envelops

Figure 4 The hourly predicted free-running temperature for the BESTEST buildings over a year

Further comparison of the results was carried out to analyze the accuracy of this quasi-steady model. In addition to the hourly free-running temperature, the absolute prediction errors of the daily average, the daily maximum temperatures, and the daily minimum temperatures of the two test buildings were also analyzed (Figure 5). This is because they are crucial design indicators for a free-running building [32]. The Figure 5 shows that the SD error bars and the quartiles of the absolute prediction error between this quasi-steady method and EnergyPlus. The error analysis indicates that the mean absolute prediction errors of the four indicators of the two BESTEST buildings are ranged from $2.3{ }^{\circ} \mathrm{C}-3.8{ }^{\circ} \mathrm{C}$. Additionally, although the maximum error can reach $4.3{ }^{\circ} \mathrm{C}-6.5{ }^{\circ} \mathrm{C}$ at the extreme conditions, the main distributions of the errors are still converged in the mean value. 


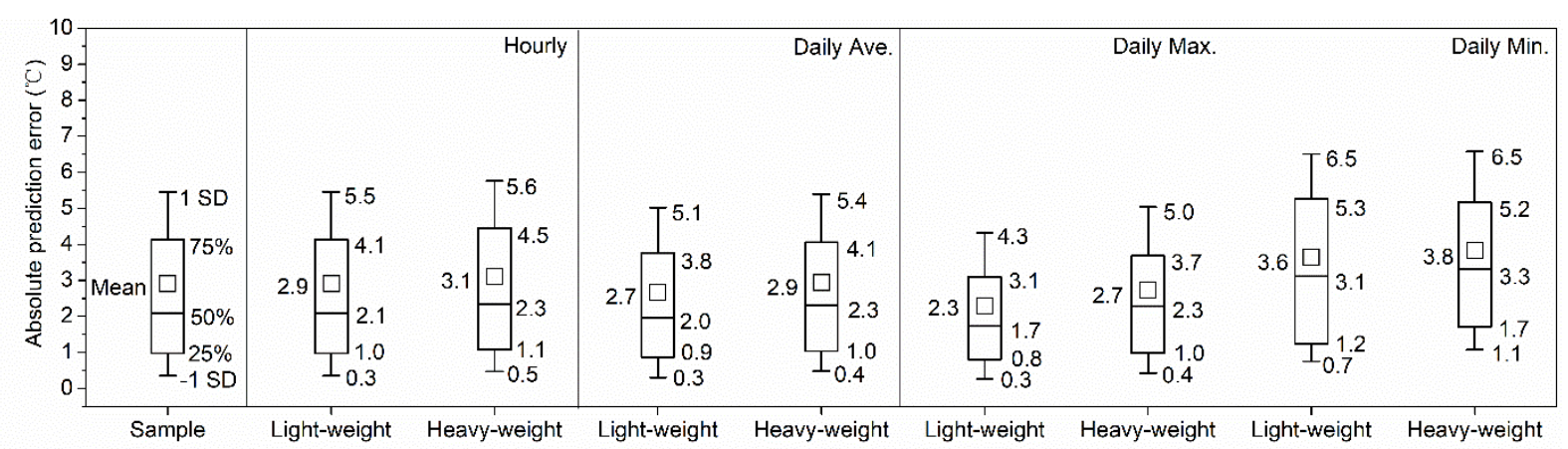

Figure 5 The absolute prediction errors of free-running temperatures between the quasi-steady model and EnergyPlus

\subsubsection{Empiricism validation}

The two experimental buildings were located in Dalian and were both south-facing. The photos and the dimensions of the two buildings are shown in Figure 6. The Building A has a heavy-weight envelope, whereas the Building B has a light-weight envelope.
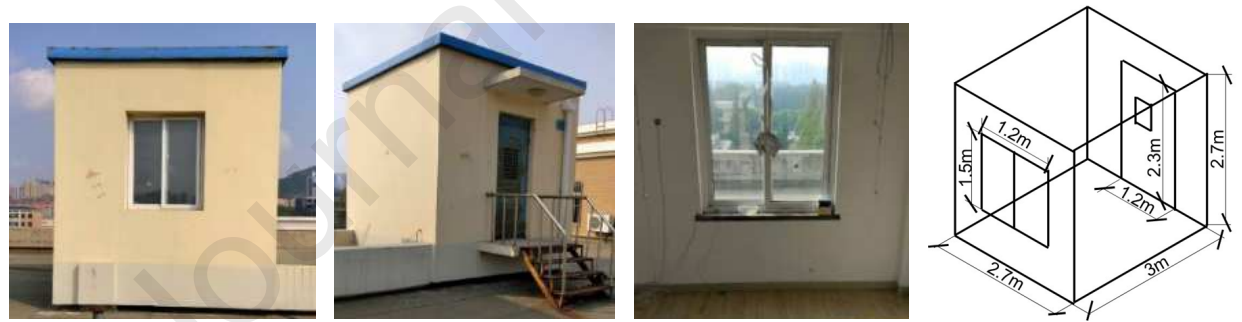

a. Building A
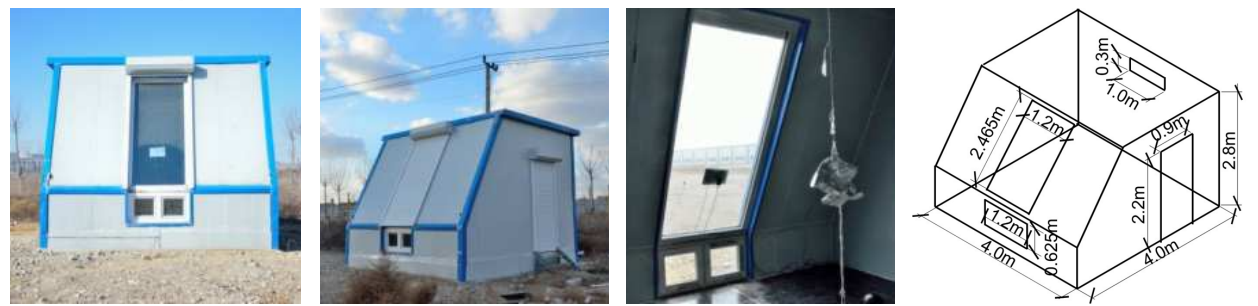

b. Building B

Figure 6 Photos and dimensions of the two experimental buildings.

The detailed configurations and thermal parameters of the envelopes are listed in Table 2, and the infiltration rate (measured using the $\mathrm{CO}_{2}$ decay method) of the heavy-weight Building $\mathrm{A}$ is $1.6 \mathrm{~h}^{-1}$, and that of the light-weight Building $\mathrm{B}$ is $0.6 \mathrm{~h}^{-1}$.

Table 2 The envelope configuration and envelope thermal performance of the two experimental buildings. 


\section{Journal Pre-proof}

\begin{tabular}{|c|c|c|c|c|}
\hline Building & Envelope & $\begin{array}{l}\text { Configuration } \\
\mathrm{mm}\end{array}$ & $\begin{array}{c}k_{\mathrm{s}} \\
\mathrm{W} /\left(\mathrm{m}^{2} \cdot \mathrm{K}\right)\end{array}$ & $\begin{array}{c}S_{\mathrm{s}} \\
\mathrm{kJ} / \mathrm{K}\end{array}$ \\
\hline \multirow{6}{*}{ A } & South wall & Concrete (200) + XPS (150) + cement mortar (15) & 0.25 & 369 \\
\hline & Other walls & Air brick $(200)+$ XPS $(150)+$ cement mortar $(15)$ & 0.23 & 359 \\
\hline & Roof & Concrete $(200)+$ air gap (200) + XPS (150) & 0.08 & 592 \\
\hline & Floor & Wooden floor $(20)+$ screed $(10)+$ concrete $(50)+$ XPS $(40)$ & 0.57 & 76 \\
\hline & Window & Double glazing plastic steel window $(S H G C=0.55)$ & 2.64 & 0 \\
\hline & Door & Wooden door & 2.64 & 0 \\
\hline \multirow{4}{*}{ B } & Wall & Polystyrene (100) + air gap (80) + polystyrene (100) & 0.20 & 61 \\
\hline & Roof & Polystyrene $(100)+$ air gap $(80)+$ polystyrene $(100)$ & 0.20 & 15 \\
\hline & Floor & $\begin{array}{c}\text { Plank }(20)+\text { air gap }(80)+\text { polystyrene }(100)+\text { air gap }(500)+ \\
\text { ground }\end{array}$ & 0.32 & 102 \\
\hline & Door \& Windows & Triple glazing plastic steel window $(S H G C=0.51)$ & 2.27 & 0 \\
\hline
\end{tabular}

This study adopts the measured data (672 hours) of the Building A in February 2014, and the measured data

(672 hours) of Building B in February 2015. During the measurements, the indoor temperatures were

recorded hourly by a hygrothermograph (accuracy $\leqslant \pm 0.3^{\circ} \mathrm{C}$ ) located at the middle of the buildings, and the outdoor weather data were recorded by two local weather stations (accuracies of $\leqslant \pm 0.4^{\circ} \mathrm{C}$ for the air temperature and $\leqslant 5 \%$ for the solar radiation). The measured data are shown in Figure 7. It can be seen from Figure 7 that free-running temperatures have a greater correlation with solar radiation and outdoor temperature. In this paper, Pearson's R (Pearson correlation coefficient) is used to obtain the association between free-running temperature, solar radiation and outdoor temperature: 0.518 and 0.515 in Building A; 0.811 and 0.525 in Building B.

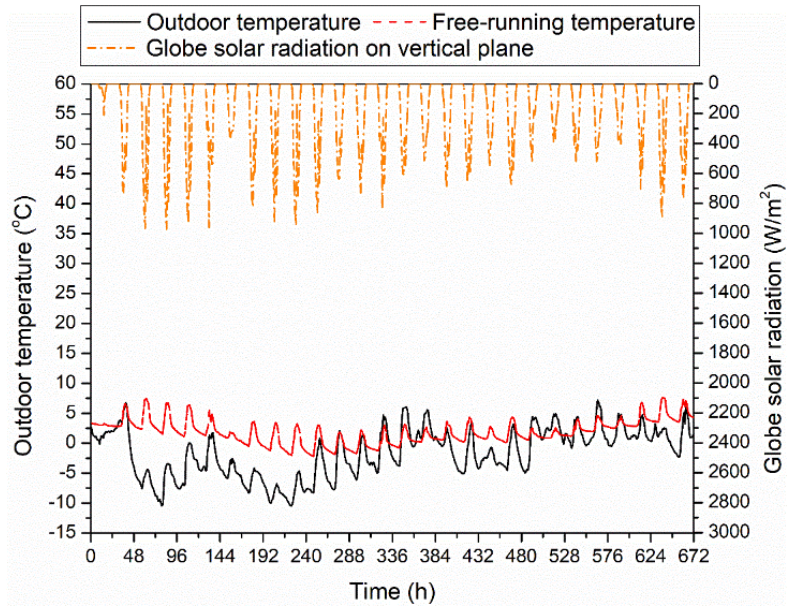

a. Building A 


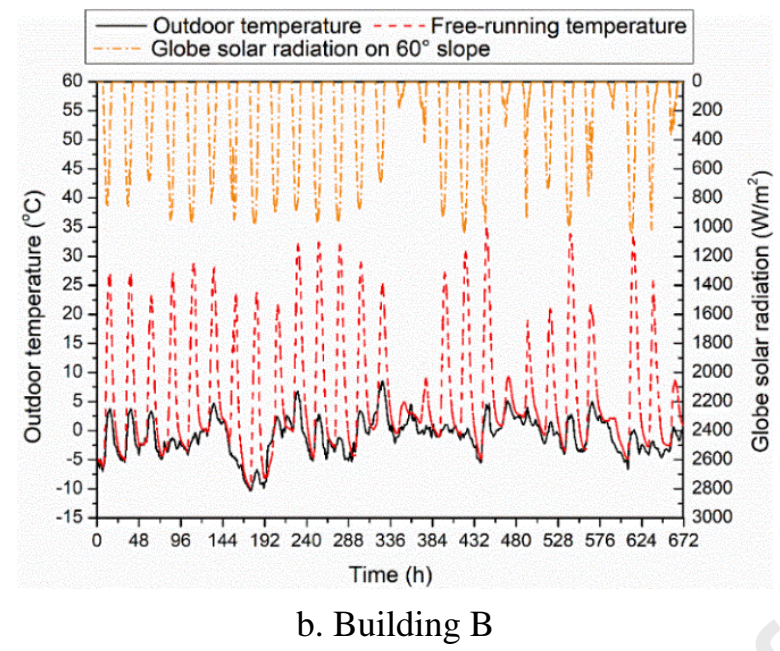

Figure 7 Relation between solar radiation and temperature in the test buildings.

According to the dimensions in Figure 6 and the envelope thermal parameters in Table 2, the combined thermal indexes $K_{\text {to }}(\mathrm{W} / \mathrm{K})$ and $S_{\text {to }}(\mathrm{kJ} / \mathrm{K})$ can be obtained. $G_{\mathrm{to}}^{j}(\mathrm{~W})$ can be obtained from the hourly measured solar radiation on the window plane and the window dimensions. Then, the initial temperatures based on the measurement, the hourly measured outdoor temperature, $G_{\mathrm{to}}^{j}(\mathrm{~W}), K_{\mathrm{to}}(\mathrm{W} / \mathrm{K})$, and $S_{\mathrm{to}}(\mathrm{kJ} / \mathrm{K})$ are substituted into the Equations (11) and (13) to predict the hourly free-running temperatures. The results shown in Figure 8 demonstrate that the variation tendency of the hourly predicted free-running temperatures is almost consistent with the measured values. In addition, the SD (Standard Deviation) error bars also show that the dispersion degree of the predicted results is in good agreement with the measured results. 


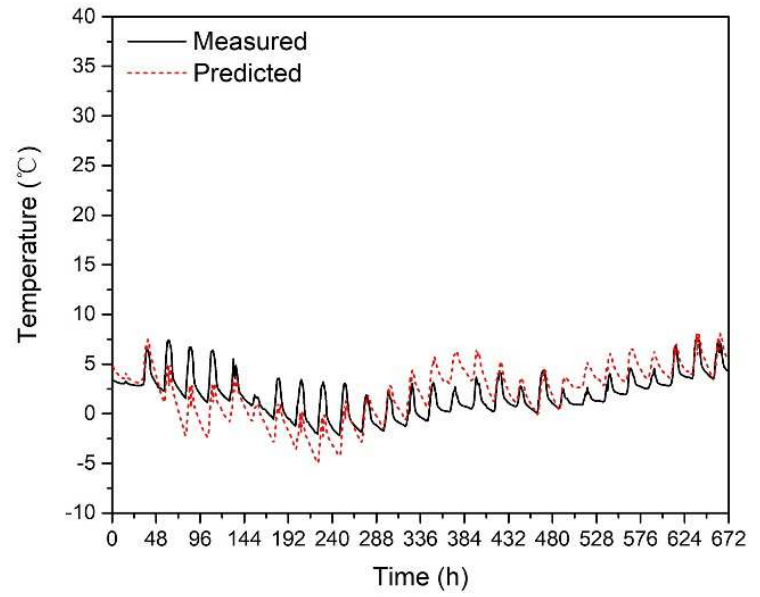

a. free-running temperature of Building A

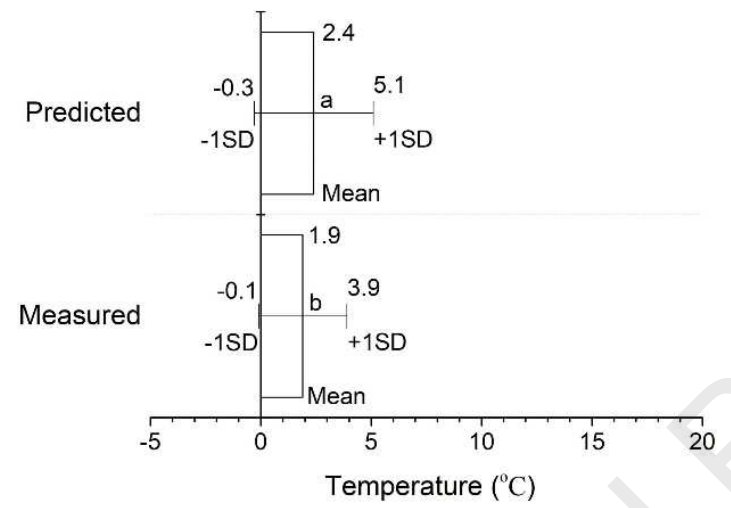

c. SD error bar for the result of Building A

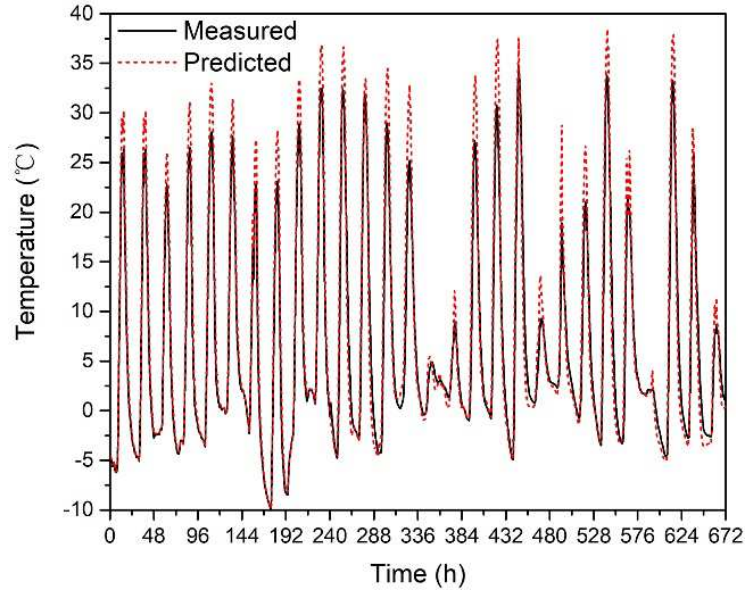

b. free-running temperature of Building B

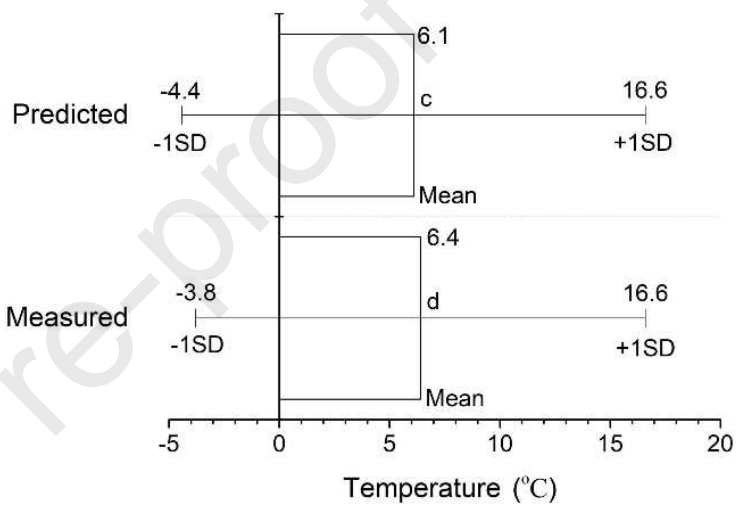

d. SD error bar for the result of Building B

Figure 8 Hourly measured and predicted free-running temperature of the two experimental buildings.

To analyze the accuracy of this quasi-steady model, the prediction results were further compared with the

Figure 9. The SD error bar (the ratio of SD is amplified to 1.2 to avoid overlapping the quartiles) and the quartiles of the absolute prediction error lie between this quasi-steady model and measured data. It indicates that the mean absolute prediction error of the four free-running temperatures of Building A ranged between $1.4{ }^{\circ} \mathrm{C}$ and $1.8{ }^{\circ} \mathrm{C}$, while they range from $0.4{ }^{\circ} \mathrm{C}$ to $4.3{ }^{\circ} \mathrm{C}$ for Building $\mathrm{B}$. The predicted daily maximum temperatures for Building B contain greater errors. This due to the lower heat capacity of the light-weight envelope with higher heat-gain intensities. Although the maximum error reached $0.8{ }^{\circ} \mathrm{C}-6.6$ ${ }^{\circ} \mathrm{C}$ at some extreme points, the main error distributions converge around the mean value. 


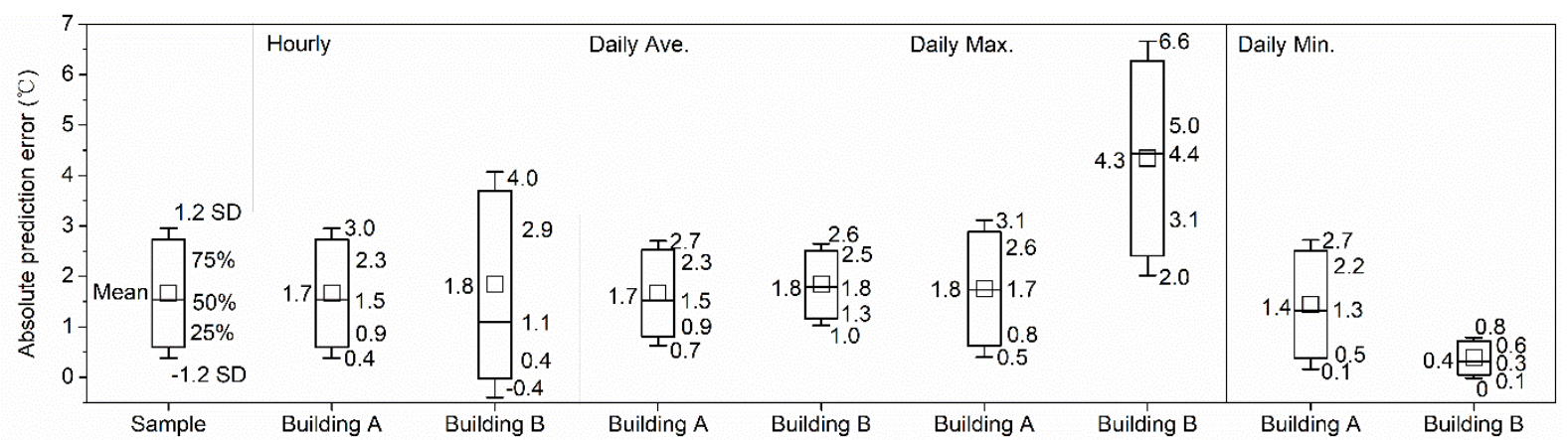

Figure 9 The absolute prediction errors of the free-running temperatures between the quasi-steady model and the measured data

As a result, although the large prediction errors occur at some times in the test, this quasi-steady model can still meet the accuracy requirements for a conceptual design. The accuracy is not required as precise as in the detailed design $[9,13]$. This method mainly focuses on the prediction of the variation tendency of hourly free-running temperatures.

\section{Simplified thermal design guideline and decision-making charts}

This quasi-steady method actually builds a correlation between the three combined thermal indexes and the free-running temperature. If a sensitivity analysis could establish an interrelationship between the combined thermal indexes and the overall thermal performance indicator based on free-running temperatures, the quantitative thermal performance of a whole building envelope including external walls, windows, ground floor and roof, can be figured out. According to those functional relationships, a thermal design guideline can also be developed as a design decision-making tool.

\subsection{Sensitivity analysis methods}

Firstly, the variables of $G_{\text {to }}(\mathrm{W}), K_{\text {to }}(\mathrm{W} / \mathrm{K})$ and $S_{\text {to }}(\mathrm{kJ} / \mathrm{K})$ were obtained from a conceptual design. The value of $G_{\text {to }}(\mathrm{W})$ is ranged by the GR (Glazing Ratio). The value of $K_{\mathrm{to}}(\mathrm{W} / \mathrm{K})$ is ranged by the different 
levels of building energy-efficiency design codes [33,34]. And the value of $S_{\mathrm{to}}(\mathrm{kJ} / \mathrm{K})$ is ranged by the thermal attributes of different construction materials given in the building thermal design codes [35].

Secondly, this quasi-steady method will be used to calculate the values of $\Delta T_{\mathrm{io}}(\mathrm{K})$ and $\alpha_{\mathrm{io}}$. The computation is based on the hourly weather data of a typical day. It uses the hourly outdoor temperatures and the hourly solar radiations at average levels during heating/cooling seasons to calculate $\Delta T_{\mathrm{io}}(\mathrm{K})$, and also adopts the hourly outdoor temperatures of a maximum daily difference and the hourly solar radiation at the maximum level during heating/cooling seasons to calculate $\alpha_{\mathrm{io}}$. Finally, the interrelationships between the three combined thermal indexes $\left(G_{\mathrm{to}}, K_{\mathrm{to}}, S_{\mathrm{to}}\right)$ and the two overall thermal performance indicators $\left(\Delta T_{\mathrm{io}}, \alpha_{\mathrm{io}}\right)$ could be obtained by a function fitting procedure. The sensitivity analysis procedure is shown in Figure 10 .

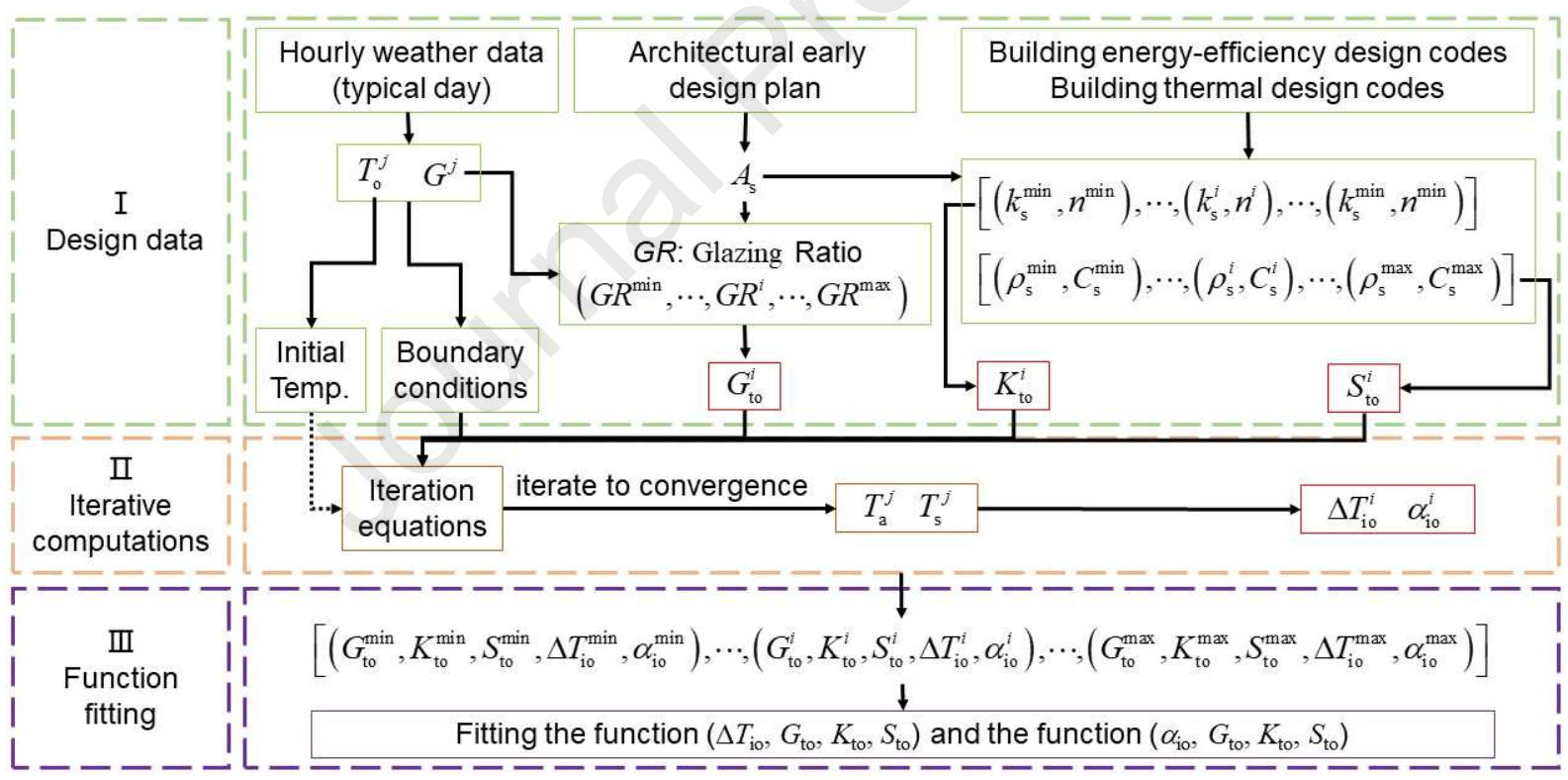

Figure 10 The sensitivity analysis procedure

\subsection{Results \& discussions}

The results that are shown in the Figure 11 demonstrates the interrelationships between the three combined thermal indexes and the two overall thermal performance indicators. The computation uses the dimensions of the test Building A (Figure 6) and the hourly weather data of a typical day in Dalian, China. The analysis 
shows that $\Delta T_{\text {io }}$ is not sensitive to $S_{\text {to }}$ as it shows in Figure 11.a, but has non-linear decreasing with $K_{\text {to }}$

(Figure 11.b), and linear growth with $G_{\mathrm{to}}$ (Figure 11.c). The results also indicate that the $\alpha_{\mathrm{io}}$ was sensitive to

$G_{\mathrm{to}}, K_{\mathrm{to}}$ and $S_{\mathrm{to}}$, as non-linear decreasing with $S_{\mathrm{to}}\left(\right.$ Figure 11.d), and linear growth with $G_{\mathrm{to}}$ (Figure 11.f). In addition, it also shows that $\alpha_{\mathrm{io}}$ linearly decreases with $K_{\mathrm{to}}$ when $S_{\mathrm{to}}=250 \mathrm{~kJ} / \mathrm{K}$, but is not sensitive to $K_{\mathrm{to}}$ when $S_{\mathrm{to}} \geq 500 \mathrm{~kJ} / \mathrm{K}$ (Figure 11.e).
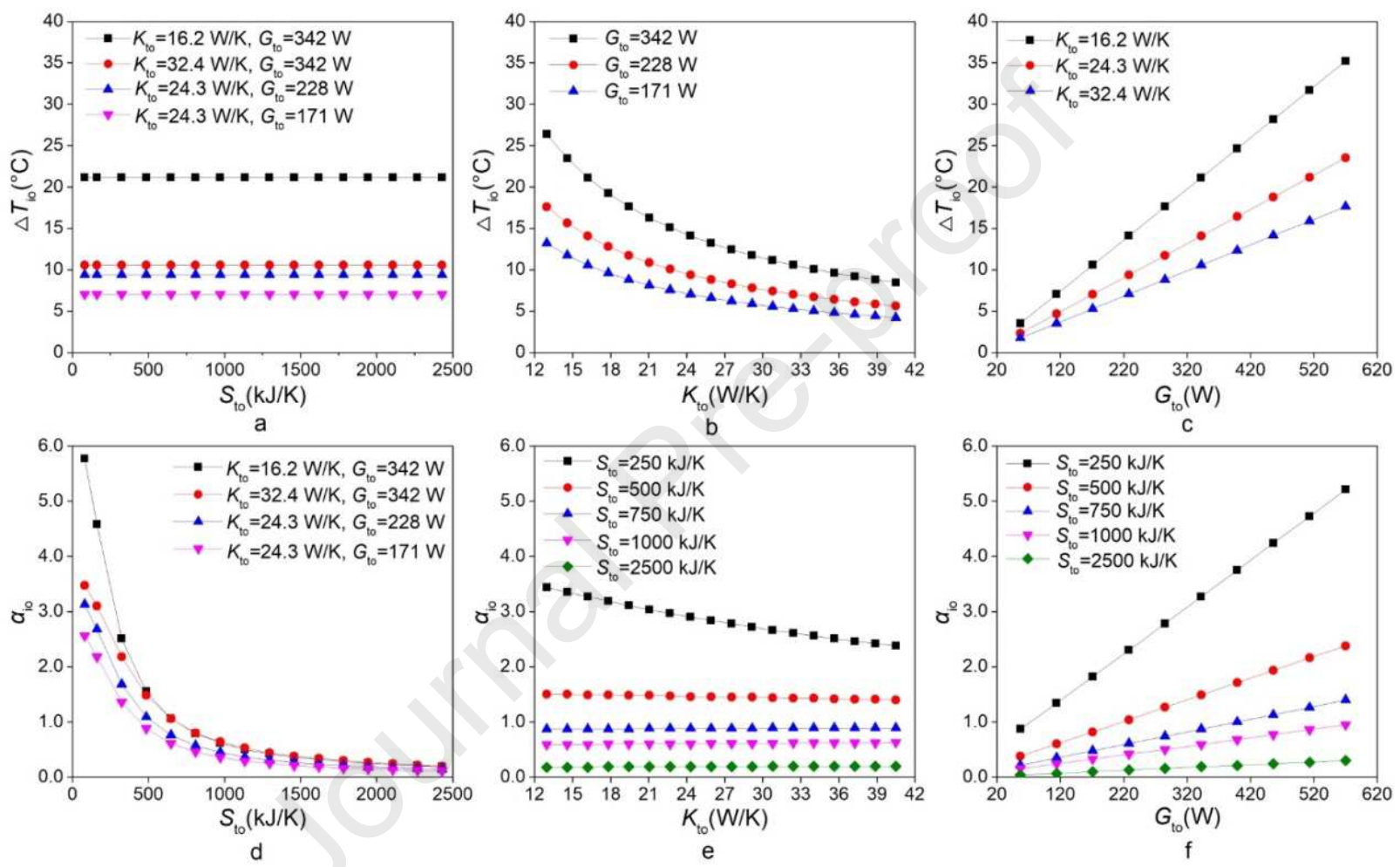

Figure 11 The relationships between the combined thermal characteristic indexes $\left(G_{\mathrm{to}}, K_{\mathrm{to}}\right.$, and $\left.S_{\mathrm{to}}\right)$ and the overall thermal performance indicators $\left(\Delta T_{\mathrm{io}}\right.$ and $\left.\alpha_{\mathrm{io}}\right)$. The $G_{\mathrm{to}}(\mathrm{W})$ used in the sensitivity analysis is the daily average value

The interrelationship between $\Delta T_{\text {io }}$ and $S_{\text {to }}$ reveals that the heat-storage effect of an average free-running temperature can be ignored. The interrelationships between $\Delta T_{\mathrm{io}}, K_{\mathrm{to}}$, and $G_{\mathrm{to}}$ demonstrate that better heat-isolation and heat-gain performance give better performance of an average free-running temperature. It also significantly increases when the heat-isolation characteristic is sufficient. The interrelationship between $\alpha_{\mathrm{io}}$ and $S_{\mathrm{to}}$ indicates that better heat-storage gives much better heat stability in a conceptual design, 
but the effect will change when the heat-storage performance is over a certain level. The interrelationships between $\alpha_{\mathrm{io}}, S_{\mathrm{to}}$, and $K_{\mathrm{to}}$ reveal that worse heat-isolation performance results in better heat stability when the heat-storage performance is small, but such effect can be ignored since the heat-storage is large enough. Additionally, the interrelationships between $\alpha_{\mathrm{io}}, S_{\mathrm{to}}$, and $G_{\mathrm{to}}$ also reveal that worse heat-gain will increase the heat stability, and a decay of the effect is identified when the heat-storage performance is increasing.

The above analysis demonstrates that the quasi-steady method makes it possible to analyze the interrelationship between free-running temperatures and the three combined thermal indexes. At present, the existing analytical methods only couple two or three of the above indicators [36-39], which cannot achieve a more accurate prediction of building thermal performance. Therefore, this requires architects to apply energy consumption simulation tools and building design tools. In fact, this is very difficult for architects. In order to achieve cooperative design, there have been researchers to develop integrated tools for both building design and energy consumption simulation [40,41].

\subsection{Decision-making charts based on the three combined thermal characteristic indexes}

\subsubsection{Decision-making charts}

Once the major building dimensions, the meteorological data of the building site, and free-running design temperatures of a conceptual design are obtained, the design decision-making charts of the three combined thermal indexes can be generated according to the interrelationships presented in the sensitivity analysis.

Based on the functional relationships of $\left(\Delta T_{\mathrm{io}}, K_{\mathrm{to}}, G_{\mathrm{to}}\right)$ in the Function Filling stage of the sensitivity analysis procedure in Figure 10 ( $S_{\text {to }}$ is ignored as it is static to $\left.\Delta T_{\mathrm{io}}\right)$, the decision-making chart (Figure 12.a) of $K_{\mathrm{to}}(\mathrm{W} / \mathrm{K})$ and $G_{\mathrm{to}}(\mathrm{W})$ is generated with the same procedures of the sensitivity analysis in Figure 10 . The design data ranges of $K_{\mathrm{to}}(\mathrm{W} / \mathrm{K})$ and $G_{\mathrm{to}}(\mathrm{W})$ on the coordinate axis were derived from the glazing ratio and 
the thermal parameters limited by the design codes. Therefore, if the desired $\Delta T_{\text {io }}(\mathrm{K})$ is known, the corresponding variables of $K_{\mathrm{to}}(\mathrm{W} / \mathrm{K})$ and $G_{\mathrm{to}}(\mathrm{W})$ can be easily found in the chart. For example, if the designed average free-running temperature is set as $18{ }^{\circ} \mathrm{C}$, the designed average outdoor temperature is -3.3 ${ }^{\circ} \mathrm{C}$ during the heating seasons in Dalian, and the desired $\Delta T_{\text {io }}$ is $21.3{ }^{\circ} \mathrm{C}$, then the coordinated values of the intersections in Figure 12.a present that the desired solution sets of $K_{\mathrm{to}}(\mathrm{W} / \mathrm{K})$ and $G_{\mathrm{to}}(\mathrm{W})$.

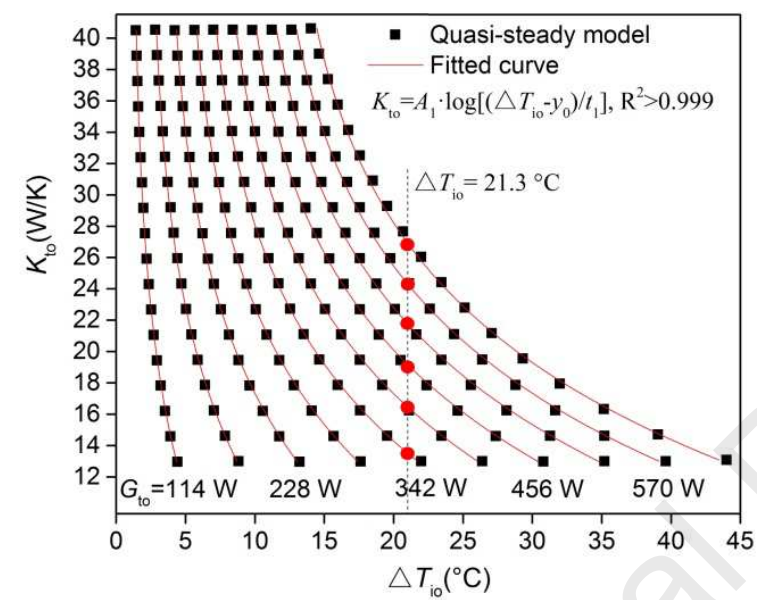

a. The decision-making chart of $G_{\mathrm{to}}(\mathrm{W}) \& K_{\mathrm{to}}(\mathrm{W} / \mathrm{K})$

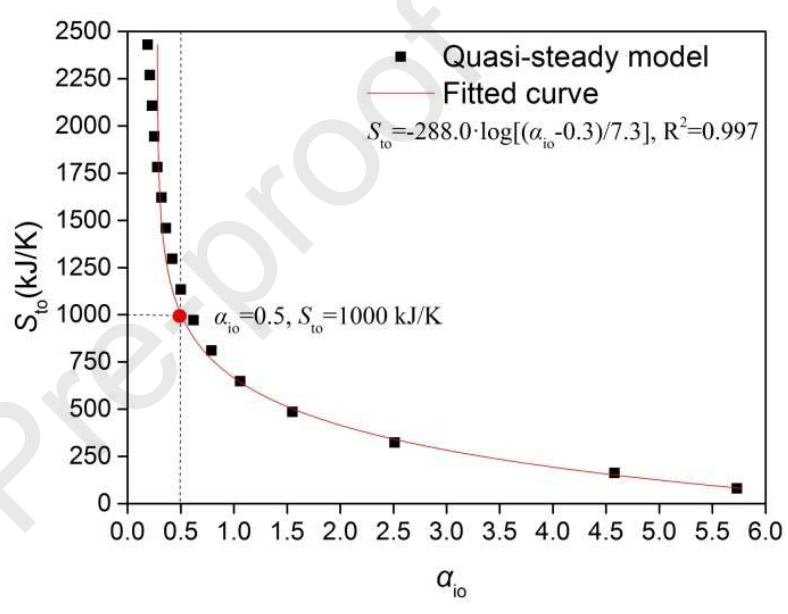

b. The decision-making chart of $S_{\mathrm{to}}(\mathrm{kJ} / \mathrm{K})$

Figure 12 The design decision-making charts of $G_{\text {to }}(\mathrm{W}), K_{\text {to }}(\mathrm{W} / \mathrm{K})$, and $S_{\text {to }}(\mathrm{kJ} / \mathrm{K})$

After $K_{\mathrm{to}}(\mathrm{W} / \mathrm{K})$ and $G_{\text {to }}(\mathrm{W})$ are determined, the decision-making chart (Figure 12.b) of $S_{\text {to }}(\mathrm{kJ} / \mathrm{K})$ is generated by using $f\left(\alpha_{\mathrm{io}}, S_{\mathrm{to}}\right)$ (Figure 11.d), with the same procedure of the sensitivity analysis in Figure 10. $S_{\text {to }}(\mathrm{W} / \mathrm{K})$ on the coordinate axis is ranged from the light-weight materials to the heavy-weight materials recommended in the Chinese thermal design code [35]. Therefore, if a desired $\alpha_{\mathrm{io}}$ is known, the corresponding $S_{\mathrm{to}}(\mathrm{W} / \mathrm{K})$ can be determined. For example, if the designed free-running temperature amplitude is set as $6{ }^{\circ} \mathrm{C}$; the maximum outdoor temperature amplitude is $12.1{ }^{\circ} \mathrm{C}$ during the heating seasons in Dalian, and the desired $\alpha_{\mathrm{io}}$ is 0.5 , then the coordinate value of the intersections in Figure 12.b is the desired value of $S_{\text {to }}(\mathrm{W} / \mathrm{K})$. 


\subsubsection{The chart validation}

The measured data of the two experimental buildings in Figure 5 were used to validate the decision-making charts. According to the building dimensions and the envelope thermal parameters in Table 2, the three combined thermal indexes of the two case-study buildings and the BESTEST buildings were calculated, and listed in Table 3.

Table 3 The three combined thermal characteristic indexes

\begin{tabular}{cccc}
\hline Building & $K_{\mathrm{to}}(\mathrm{W} / \mathrm{K})$ & $S_{\mathrm{to}}(\mathrm{kJ} / \mathrm{K})$ & $G_{\mathrm{to}}(\mathrm{W})$ \\
\hline $\mathrm{A}$ & 35.9 & 1350 & 143 \\
$\mathrm{~B}$ & 33.6 & 157 & 237 \\
BESTEST (light mass) & 86.5 & 1839 & 411 \\
BESTEST (heavy mass) & 86.5 & 2900 & 411 \\
\hline
\end{tabular}

The designed values for the two experimental buildings can come from the decision-making charts (Figure 12) directly. The average outdoor temperature in the test period was $-1.6{ }^{\circ} \mathrm{C}$, and the daily maximum amplitude of outdoor temperature during this measurement was $10.8{ }^{\circ} \mathrm{C}$, as shown in Figure 7. The designed and measured $\Delta T_{\mathrm{io}}(\mathrm{K})$ and $\alpha_{\mathrm{io}}$ are both given in Table 4 , which shows that the design error of $\Delta T_{\mathrm{io}}$ (K) for Building A is $0.5{ }^{\circ} \mathrm{C}(=4.0-3.5)$, while for Building B it is $2.3{ }^{\circ} \mathrm{C}(=9.6-7.3)$. It also indicates that the design error of $\alpha_{\mathrm{io}}$ for Building A is $0.1(=0.5-0.4)$, while for Building B it is $0.3(=3.8-3.5)$. In addition, the design indicators of overall building thermal performance were calculated for the BESTEST buildings. The results (Table 4) showed that the $\alpha_{\mathrm{io}}$ in the two buildings are mainly caused by $S_{\mathrm{to}}$.

Table 4 The design and measured indicators of overall building thermal performance

\begin{tabular}{ccccccc}
\hline Index & \multicolumn{2}{c}{ Experimental Building A } & \multicolumn{2}{c}{ Experimental Building B } & $\begin{array}{c}\text { BESTEST } \\
\text { (light weight) }\end{array}$ & $\begin{array}{c}\text { BESTEST } \\
\text { (heavy weight) } \\
\end{array}$ \\
& Design & Measured & Design & Measured & Design & Design \\
\hline$\Delta T_{\text {io }}\left({ }^{\circ} \mathrm{C}\right)$ & 4.0 & 3.5 & 9.6 & 7.3 & 11.7 & 11.7 \\
$\alpha_{\text {io }}$ & $\leqslant 0.4$ & $\leqslant 0.5$ & $\leqslant 3.8$ & $\leqslant 3.5$ & 0.3 & 0.2 \\
\hline
\end{tabular}


By checking with these decision-making charts, architect can quickly acquire the design indicators of an overall building thermal performance. However, for different climate and building sizes, the decision-making charts may need to be adjusted. The method of obtaining the decision-making charts can be developed into a software in the future. When architects input basic building information and weather data in a concept design, the software could quickly obtain three characteristic parameters and decision-making charts for architects to determine if their designs are good enough or not in terms of energy efficiency. The two decision-making charts developed in this research are suitable for quickly determining the thermal performance parameters of a building envelope with basic design information and indoor human comfort targets. Additionally, this method is not only a handy method for architects to predict the thermal performance of their conceptual design, but also presents a unique and reverse approach for the energy performance prediction by setting up a human comfort target first, and then determining the building envelop materials in a conceptual design.

\section{Conclusions}

This study has developed a unique and simplified quasi-steady method based on free-running temperatures, which can be used as an easy and alterative means by architects and designers in the conceptual design stage of a building project to assess an integrated building energy efficiency performance. The comparison between this quasi-steady method and the conventional simulation demonstrates that this quasi-steady method can easily predict if a design can achieve the targeted human-comfort based on the free-running temperatures which are worked out with the building envelope structures. This method can easily predict the free-running temperatures of a designed building and generate two decision-making charts of thermal 
design parameters. The major differences from the existing thermal prediction methods and tools can be addressed as below:

1. The quasi-steady method requests relatively much less information or parameters (only the structural parameters of building envelopes and building dimensions) rather than a whole design model requested in some thermal performance analysis software.

2. This quasi-steady method enables a quick prediction of the thermal performance with MS Excel for a conceptual design, rather than a complex function programming usually requested in those methods with software tools.

3. This research develops a unique method that is based on three simplified and combined indexes $\left(G_{\mathrm{to}}\right.$, $K_{\mathrm{to}}$, and $\left.S_{\mathrm{to}}\right)$ and the interrelationships with two integrated thermal performance indicators $\left(\Delta T_{\mathrm{io}}\right.$, and $\alpha_{\mathrm{io}}$ ) of a building, and generates two thermal performance prediction charts which enables architects to predict the thermal performance of their design in the conceptual design stage.

As mentioned in discussion, this theoretical and experimental study can be further developed as a software with convenient user interfaces, which can be easily manipulated by practical architects and building engineers. The method can be applied in the early design stage, such as design briefing and conceptual design to notify the clients the possible building envelope materials which could be chosen. This will also give more accurate implication on the costs of the building at the early design stage. However, the following limitations of the study should also be noted. Firstly, it needs to be validated and adjusted with the weather data and different building envelops in different cities in China. Secondly, other possible factors may be considered in this quasi-steady method in future to promote the prediction precision of conceptual thermal designs, such as the design of passive heating and cooling systems, and passive control strategies. Thirdly, this method also has to be further tested, adjusted and improved with different types and complexities of buildings. 


\section{Acknowledgement}

This study was supported by "the 13th Five-Year" National Science Technology Major Project of China (No. 2018YFD1100701), National Natural Science Foundation of China (No. 51978121).

\section{References}

[1] C. Ghiaus, F. Allard, Potential for free-cooling by ventilation, Sol. Energy. 80 (2006) 402-413. doi:https://doi.org/10.1016/j.solener.2005.05.019.

[2] C. Ghiaus, Free-running building temperature and HVAC climatic suitability, Energy Build. 35 (2003) 405-411. doi:https://doi.org/10.1016/S0378-7788(02)00110-X.

[3] C. Inard, J. Pfafferott, C. Ghiaus, Free-running temperature and potential for free cooling by ventilation: A case study, Energy Build. $43 \quad$ (2011) 2705-2711. doi:https://doi.org/10.1016/j.enbuild.2011.06.017.

[4] C. Ghiaus, Equivalence between the load curve and the free-running temperature in energy estimating methods, Energy Build. 38 (2006) 429-435. doi:https://doi.org/10.1016/j.enbuild.2005.08.003.

[5] M. Germano, C. Ghiaus, C.-A. Roulet, F. Allard, Natural Ventilation Potential of Urban Buildings, Int. J. Vent. 4 (2005) 49-56. doi:https://doi.org/10.1080/14733315.2005.11683698.

[6] L.-S. Wang, P. Ma, E. Hu, D. Giza-Sisson, G. Mueller, N. Guo, A study of building envelope and thermal mass requirements for achieving thermal autonomy in an office building, Energy Build. 78 (2014) 79-88. doi:https://doi.org/10.1016/j.enbuild.2014.04.015.

[7] B. Levitt, M. Ubbelohde, G. Loisos, N. Brown, Thermal autonomy as metric and design process, in: CaGBC Natl. Conf. Expo Push. Boundary-Net Posit. Build., 2013: pp. 47-58.

[8] W. Natephra, N. Yabuki, T. Fukuda, Optimizing the evaluation of building envelope design for thermal 
performance using a BIM-based overall thermal transfer value calculation, Build. Environ. 136 (2018) 128-145. doi:https://doi.org/10.1016/j.buildenv.2018.03.032.

[9] B. Toth, R. Drogemuller, J.H. Frazer, Information dependencies between architects and services engineers for early design evaluation: a framework for an energy design tool for architects, in: New Front. Proc. 15th Int. Conf. Comput. Archit. Des. Res. Asia CAADRIA 2010, Association for Research in Computer-Aided Architectural Research in Asia (CAADRIA), 2010: pp. 313-322.

[10] V. Harish, A. Kumar, A review on modeling and simulation of building energy systems, Renew. Sustain. Energy Rev. 56 (2016) 1272-1292. doi:https://doi.org/10.1016/j.rser.2015.12.040.

[11] S. Seyedzadeh, F.P. Rahimian, I. Glesk, M. Roper, Machine learning for estimation of building energy consumption and performance: a review, Vis. Eng. 6 (2018) 5. doi:https://doi.org/10.1186/s40327-018-0064-7.

[12] R. Evins, A review of computational optimisation methods applied to sustainable building design, Renew. Sustain. Energy Rev. 22 (2013) 230-245. doi:https://doi.org/10.1016/j.rser.2013.02.004.

[13] V. Machairas, A. Tsangrassoulis, K. Axarli, Algorithms for optimization of building design: A review, Renew. Sustain. Energy Rev. 31 (2014) 101-112. doi:https://doi.org/10.1016/j.rser.2013.11.036.

[14] Y. Huang, J. Niu, Optimal building envelope design based on simulated performance: History, current $\begin{array}{lllllll}\text { status and new potentials, Energy } & \text { Build. } 117 & \text { (2016) 387-398. }\end{array}$ doi:https://doi.org/10.1016/j.enbuild.2015.09.025.

[15] F. Kheiri, A review on optimization methods applied in energy-efficient building geometry and envelope design, Renew. Sustain. Energy Rev. $92 \quad$ (2018) 897-920. doi:https://doi.org/10.1016/j.rser.2018.04.080.

[16] T. Østergård, R.L. Jensen, S.E. Maagaard, Building simulations supporting decision making in early 
design-A review, Renew. Sustain. Energy Rev. $61 \quad$ (2016) 187-201. doi:https://doi.org/10.1016/j.rser.2016.03.045.

[17] H. Zhao, F. Magoulès, A review on the prediction of building energy consumption, Renew. Sustain. Energy Rev. 16 (2012) 3586-3592. doi:https://doi.org/10.1016/j.rser.2012.02.049.

[18] H. Wang, Z.J. Zhai, Advances in building simulation and computational techniques: A review between 1987 and 2014, Energy Build. 128 (2016) 319-335. doi:https://doi.org/10.1016/j.enbuild.2016.06.080.

[19] J.F. Kreider, P.S. Curtiss, A. Rabl, Heating and cooling of buildings: design for efficiency, McGrawHill, New York, USA, 1994.

[20] K.A. Antonopoulos, E.P. Koronaki, On the dynamic thermal behaviour of indoor spaces, Appl. Therm. Eng. 21 (2001) 929-940. doi:https://doi.org/10.1016/S1359-4311(00)00091-0.

[21] T.R. Nielsen, Simple tool to evaluate energy demand and indoor environment in the early stages of building design, Sol. Energy. 78 (2005) 73-83. doi:https://doi.org/10.1016/j.solener.2004.06.016.

[22] ISO 13790: 2008, Energy Performance Of Buildings - Calculation Of Energy Use For Space Heating And Cooling, (2008). www.iso.org.

[23] P. Heiselberg, H. Brohus, A. Hesselholt, H. Rasmussen, E. Seinre, S. Thomas, Application of sensitivity analysis in design of sustainable buildings, Renew. Energy. 34 (2009) 2030-2036. doi:https://doi.org/10.1016/j.renene.2009.02.016.

[24] W. Tian, A review of sensitivity analysis methods in building energy analysis, Renew. Sustain. Energy Rev. 20 (2013) 411-419. doi:https://doi.org/10.1016/j.rser.2012.12.014.

[25] J.C. Lam, S.C.M. Hui, Sensitivity analysis of energy performance of office buildings, Build. Environ. 31 (1996) 27-39. doi:https://doi.org/10.1016/0360-1323(95)00031-3.

[26] I.O. for Standardization, ISO 13786:2008, Thermal Performance Of Building Components - Dynamic 
Thermal Characteristics - Calculation Methods, (2008).

[27] E. Kossecka, J. Kosny, Influence of insulation configuration on heating and cooling loads in a continuously used building, Energy Build. $34 \quad$ (2002) 321-331. doi:https://doi.org/10.1016/S0378-7788(01)00121-9.

[28] ANSI/ASHRAE140:2001, Standard method of Test for the evaluation of building energy analysis computer programs, Am. Soc. Heating, Refrig. Air-Conditioning Eng. (2001).

[29] T. Kusuda, NBSLD-The computer program for heating and cooling loads for buildings, Washington $\mathrm{DC}$, 1976. https://www.osti.gov/biblio/7217916-nbsld-computer-program-heating-cooling-loads-buildings.

[30] S. Obyn, G. van Moeseke, Variability and impact of internal surfaces convective heat transfer coefficients in the thermal evaluation of office buildings, Appl. Therm. Eng. 87 (2015) 258-272. doi:https://doi.org/10.1016/j.applthermaleng.2015.05.030.

[31] Energyplus, EnergyPlus Engineering Reference, $\quad$ October. $152 \quad$ (2010) 1. https://bigladdersoftware.com/epx/docs/8-6/engineering-reference.

[32] E. Krüger, B. Givoni, Thermal monitoring and indoor temperature predictions in a passive solar building in an arid environment, Build. Environ. 43 (2008) 1792-1804. doi:https://doi.org/10.1016/j.buildenv.2007.10.019.

[33] P.H. Institute, Criteria for the passive house, EnerPHit and PHI low energy building standard, (2016). http://www.passiv.de/downloads/03_building_criteria_en.pdf.

[34] Ministry of Housing and Urban-Rural Development of the Republic of China, Design Standard for Energy Efficiency of Residential Buildings in Severe Cold and Cold Zones(JGJ26-2018), Beijing, 2018. www.jianbiaoku.com/webarbs/book/37/3996347.shtml. 
[35] Ministry of Housing and Urban-Rural Development of the Republic of China, Code for thermal design of civil building(GB50176-2016), $\quad$ (2016) 13-14. http://www.jianbiaoku.com/webarbs/book/1033/2904544.shtml.

[36] P. Hietaharju, M. Ruusunen, K. Leiviskä, A dynamic model for indoor temperature prediction in buildings, Energies. 11 (2018) 1477. doi:https://doi.org/10.3390/en11061477.

[37] A. Foucquier, S. Robert, F. Suard, L. Stéphan, A. Jay, State of the art in building modelling and energy performances prediction: A review, Renew. Sustain. Energy Rev. 23 (2013) 272-288. doi:https://doi.org/10.1016/j.rser.2013.03.004.

[38] C. Underwood, F. Yik, Modelling methods for energy in buildings, John Wiley \& Sons, 2008.

[39] H. Krstić, M. Teni, Review of Methods for Buildings Energy Performance Modelling, IOP Conf. Ser. Mater. Sci. Eng. 245 (2017) 42049. doi:https://doi.org/10.1088/1757-899x/245/4/042049.

[40] S. Attia, A tool for design decision making: zero energy residential buildings in hot humid climates, Presses univ. de Louvain, 2012.

[41] C. Struck, P.J.C.J. de Wilde, C.J. Hopfe, J.L.M. Hensen, An investigation of the option space in conceptual building design for advanced building simulation, Adv. Eng. Informatics. 23 (2009) 386395. doi:https://doi.org/10.1016/j.aei.2009.06.004. 


\section{Highlights}

1. A quasi-steady method is developed to predict hourly free-running temperatures.

2. The quasi-steady method was validated by BESTEST buildings and two test buildings.

3. The connection of these thermal indexes is established via a sensitivity analysis.

4. The two decision-making charts for a conceptual design are generated.

5. It's a unique and simplified prediction of thermal performance for a conceptual design. 


\section{Declaration of interests}

The authors declare that they have no known competing financial interests or personal relationships that could have appeared to influence the work reported in this paper.

囚The authors declare the following financial interests/personal relationships which may be considered as potential competing interests:

The authors declare that they have no known competing financial interests or personal relationships that could have appeared to influence the work reported in this paper 